\title{
A Quantitative Trait Locus Analysis of the Dopamine Transporter Gene in Adults with ADHD
}

\author{
Pierandrea Muglia, M.D., Umesh Jain, M.D., Becky Inkster, B.Sc., and James L. Kennedy, M.D.
}

Numerous lines of evidence have shown that attention deficit hyperactivity disorder $(A D H D)$ is a highly heritable disorder, whether it is considered as a category or a dimension. We tested for an association between the dopamine transporter gene (DAT1) and ADHD considering the disorder as categorical as well as a continuous trait. Genotypes for the $D A T 1$ variable number of tandem repeat (VNTR) alleles, along with Brown Attention Deficit Disorder Scale (BADDS) and Wender Utah Rating Scale (WURS) scores were available for 152 adult ADHD patients. In 72 of these patients DNAs from at least one parent were accessible to perform a family-based analysis (FBAT). The mean quantitative trait values of the whole sample of singleton patients were compared among the specific genotype groups using ANOVA. The family-based analysis did not reveal any association between DAT1 alleles and ADHD either when it was considered as a dichotomous trait $(Z=0.16, p=.86)$ or as a continuous trait (Wender Scale $Z=-1.67, p=.09$; Brown ADD Scale $Z=0.28, p=.77$ ). No significant differences were detected in the mean symptom scores among the specific genotype groups. The results from our study do not support a major role for the DAT1 VNTR alleles in our sample of adult ADHD. In view of several positive reports in child $A D H D$, more work is required to elucidate the potential role of the DAT1 VNTR as a risk factor in ADHD.

[Neuropsychopharmacology 27:655-662, 2002] (C) 2002 American College of Neuropsychopharmacology. Published by Elsevier Science Inc.
KEY WORDS: Attention deficit hyperactivity disorder; Adults; Genetics; Dopamine transporter gene; Quantitative Trait Analysis

Attention deficit hyperactivity disorder (ADHD) is a highly prevalent disorder in childhood characterized by severe impairment in attention span and/or marked hyperactive and impulsive behavior not appropriate for

From the Neurogenetics Section (PM, BI, JLK) and the Adult ADHD Clinic (PM, UJ, BI), Centre for Addiction and Mental Health, Department of Psychiatry, University of Toronto, Toronto, Canada.

Address correspondence to: Dr. James L. Kennedy, Neurogenetics Section, Clarke Site Centre for Addiction and Mental Health, University of Toronto, 250 College Street, R-30, Toronto, Ontario, Canada M5T 1R8. Tel.: (416) 979-4987; Fax: (416) 979-4666; E-mail: james_kennedy@camh.net

Received December 4, 2001; revised March 7, 2002; accepted March 7, 2002.

Online publication: 3/11/02 at www.acnp.org/citations/ Npp031102265. age (American Psychiatric Association 1994). Several follow-up studies that evaluated the persistence of the disorder in adolescence and adulthood have revealed that one third to two thirds of ADHD children do not recover from the disorder (Gittelman et al. 1985; Barkley et al. 1990; Mannuzza et al. 1991; Weiss et al. 2000). However, the percentage of retained diagnosis in adulthood varies across studies. The relative lack of specific validated criteria for adult ADHD and the different definitions used to evaluate the persistence of the disorder may have contributed to these discrepancies. In the fourth edition of the DSM the criteria for ADHD are applicable to both adults and children. However, because the phenomenology in ADHD varies across the life span in quality of symptoms as well as in degree of severity (Weiss et al. 1985; Biederman et al. 2000), specific criteria for adults appear to be necessary. Even if there is little agreement on the proportion of children that 
continue to suffer from the disorder in adulthood, several lines of evidence have shown that adult ADHD represents a mental disorder of significant clinical relevance. Adult ADHD patients have at least twofold increased prevalence for a number of co-morbid psychiatric disorders (Weiss et al. 1985; Mannuzza et al. 1991; Biederman et al. 1993). These include: an increased risk compared with the general population of around 10 times for antisocial personality disorder, four times for substance and alcohol abuse (Weiss et al. 1985; Biederman et al. 1993), and approximately five times for mood and anxiety disorder (Biederman et al. 1991, 1993).

The decline of ADHD with increasing age may be advantageous to genetic investigations because the persistent form of the disorder is less common and appears to have a greater genetic liability. Probands with the persistent form of the disorder have a higher rate of ADHD in their relatives compared with the rate in relatives of child ADHD probands (Faraone et al. 2000).

Compelling evidence from genetic epidemiology studies have shown that ADHD aggregates in families (Thapar et al. 1999). The concordance for ADHD in twins has indicated that the disorder has heritability between 0.64 and 0.98, suggesting a large genetic influence (Willerman 1973; Goodman and Stevenson 1989; Gillis et al. 1992; Levy et al. 1997; Hay et al. 2001). Twin studies have also determined a genetic component for attention and impulsivity-hyperactivity (Goodman and Stevenson 1989; Levy et al. 1997; Sherman et al. 1997; Hay et al. 2001). Adoption studies have excluded any major contribution from shared environmental factors in predisposition to ADHD, further emphasizing the role of the genetic component (Welner et al. 1977; Biederman et al. 1990; Sprich et al. 2000). In a recent segregation analysis of ADHD families, several genetic models were supported when the disorder was considered as a quantitative trait (Maher et al. 1999). This study confirmed the evidence from a previous report conducted in a large Australian twin sample (Levy et al. 1997) in which a genetic contribution for a continuous dimension of the disorder was shown. It is therefore likely that the ADHD diagnosis represents an extreme of a trait distributed continuously in the population. In these circumstances, the use of dimensional measures of ADHD symptoms represents a valid approach to the identification of quantitative trait loci (QTL) underlying the disorder or symptom clusters.

Numerous findings support the involvement of the catecholamine systems in ADHD (Pliszka et al. 1996; Biederman and Spencer 1999) and converging evidence supports a key role for meso-cortical dysfunction (Castellanos 1997). A pharmacodynamic property of methylphenidate is the inhibition of the monoamine transporters with the highest affinity for the dopamine transporter (Gatley et al. 1996). The efficacy of methylphenidate in improving ADHD symptoms together with its principal mechanism of action have pointed to the dopamine transporter gene (SLC6A3, alias DAT1) as a primary candidate to study in ADHD. DAT1 has been mapped to chromosome 5p15.3 (Giros et al. 1992; Vandenbergh et al. 1992), and is comprised of 15 exons. It contains a 40 base pair variable number of tandem repeats in the 3'-untranslated region (3'UTR-VNTR) (Vandenbergh et al. 1992). Alleles with 3 to 13 repeats have been described, but the alleles with 10 and 9 repeats are the most frequent across several populations studied (Kang et al. 1999; Mitchell et al. 2000).

Cook et al. (1995) reported the 10-repeat allele of the DAT1 3'UTR-VNTR to be associated with the disorder. The association was replicated in two samples, one from Ireland (Gill et al. 1997; Daly et al. 1999), and one from the U.K. (Curran et al. 2001). It was partially replicated in a sample from the U.S. (Waldman et al. 1998) and in one from Canada (Barr et al. 2001) where the association was present with a haplotype that contained the 10-repeat allele. Waldman et al. (1998) regressed the 10-repeat allele association with hyperactive-impulsive and inattentive symptom dimensions and found higher scores of hyperactive-impulsive symptoms in the patients with the 10-repeat allele. The DAT1 association, however, was not replicated in five different data sets: (Palmer et al. 1999; Holmes et al. 2000; Swanson et al. 2000; Curran et al. 2001; Roman et al. 2001). These contrasting results across different data sets could be determined by the heterogeneous nature of the disorder as identified by the current diagnostic criteria. As suggested by Waldman et al. findings (Waldman et al. 1998), for example, the DAT1 10-repeat allele may be associated only with specific subtypes of the disorder or only with more severe variants of the disorder.

In the present study we performed a family-based linkage disequilibrium analysis between the DAT1 3'UTR-VNTR alleles and ADHD in a sample of families with adult ADHD probands. The adult ADHD phenotype was considered as a qualitative as well as a quantitative trait. The quantitative trait of ADHD was derived from the Brown Attention Deficit Disorder Scale (BADDS), adult version (Brown 1996) and the Wender Utah Rating Scale (WURS) (Ward et al. 1993). In addition, a quantitative trait locus analysis of DAT1 VNTR alleles was performed in a partially independent sample of singleton adult ADHD patients. The use of the quantitative phenotype will test for association between the DAT1 3'UTR VNTR alleles and dimensions of ADHD or specific core symptoms.

\section{SUBJECTS AND METHODS}

\section{Subjects}

This study was approved by the Centre for Addiction and Mental Health (CAMH) human subjects ethics 
committee. All the subjects were clinician-referred to the Adult and Adolescent ADHD Research Program of the $\mathrm{CAMH}$, an affiliate teaching hospital of the University of Toronto, for assessment. All subjects that participated had at least one first-degree relative willing to participate and collaborate in providing the collateral childhood history of the patients. After signing the informed consent, the patients underwent an extensive evaluation which has been described previously in detail (Muglia et al. 2000). The diagnosis of ADHD was based on fulfilling the ADHD DSM-IV criteria both at the time of the interview and during childhood, as recalled by the patient and by at least one first-degree relative involved in the study. For broad assessment of psychiatric conditions, the Structured Clinical Interview for DSM-IV (axis I) was administered by a trained psychiatrist (U.J.) with extensive experience in adult ADHD. Patients diagnosed with other psychiatric conditions, with the exception of dysthymia, were not considered for this study. In the five years period of recruitment at our adult ADHD clinic, approximately 30 percent of referrals were not included in our sample because of the presence of comorbid conditions or because they did not meet the criteria for the disorder. The Brown Attention Deficit Disorder Scale and the Wender Utah Rating Scale were completed by all the patients. The Brown ADD Scale consists of a 40-item self report that measures core symptoms of ADHD. The scale has been normalized using 142 adult ADHD patients and 143 healthy subjects, showing a good internal consistency and a good test-retest reliability (Brown 1996). The total score can range from 0 to 120; patients that score $>55$ are highly probable to suffer from ADHD, those between 40 and 54 have 'probable' ADHD, and those $<40$ have 'possible' ADHD. Five different adult ADHD dimensions are present in the scale: organizing and activating to initiate work, sustaining attention and concentration, sustaining energy and effort, managing affective interference, and utilizing working memory and accessing recall. The Wender Utah Rating Scale is a 61-item self-report questionnaire that retrospectively assesses childhood ADHD symptoms, as well as frequently associated behavioral, medical and learning problems. The validity and specificity of the WURS has been tested in a group of adults with ADHD versus patients with major depression, and healthy controls (Ward et al. 1993). Among the 61 WURS items, the 25 items that have shown the greatest mean difference between ADHD and non-ADHD patients has been used in our study. A total score higher than 46 on the 25 -item scale is able to identify $86 \%$ of the ADHD patients (Ward et al. 1993). For the present study genotypes for the DAT1 VNTR along with BADDS and WURS 25 item scores were available for 152 adult ADHD patients (mean age: 38.24; S.D. \pm 11.70 ; range: 19 to 69 ; male/female $=99$ / $53)$, of which $98 \%$ were mixed European Caucasian while the remaining three subjects consisted of two African Americans and one Caribbean.

For the family-based part of the study 102 pedigrees were available with a total of 338 individuals of which 126 were affected by ADHD. The structure of families in our sample consisted mainly of nuclear families (45 triads and 36 parent-proband pairs), 16 families with multiple sibs and five three-generation families. In the total number of 126 affected individuals 30 were non adults, that were assessed because they had one of their parents referred to our clinic.

\section{Laboratory Methods}

Blood samples were drawn from the patients and the relatives that participated in the study and the DNA was extracted following standard procedures. The DNA region containing the $40 \mathrm{bp} 3^{\prime} \mathrm{UTR}-\mathrm{VNTR}$ of the DAT1 was amplified using the polymerase chain reaction and then genotyped using methods previously published (Vandenbergh et al. 1992). The genotypes were assigned blind to the family structure and to the affection status of the subjects.

\section{Statistical Methods}

A family-based association strategy was used to test for the presence of association between the DAT1 3'UTRVNTR and adult ADHD in the nuclear families. The study was performed using both categorical and dimensional measures of the disorder. The family-based association strategy that makes use of nuclear families consisting of an affected proband and their biological parents represents a well established approach, and it is more powerful than case-control designs in the presence of population substructure (Bacanu et al. 2000). A number of approaches that incorporate quantitative phenotypes into the TDT analysis have been developed (Allison 1997; Rabinowitz 1997; Waldman et al. 1999) and have been implemented in available software programs (Abecasis et al. 2000; Lake et al. 2000). The Family-Based Association Test (FBAT) is a recently developed software that can analyze for association pedigrees with heterogeneous family structure. Furthermore, FBAT allows the analysis of the phenotype as a qualitative or as a quantitative trait (Horvath et al. 2001). In the present study, we made use of the FBAT program (version 1.0) to perform the qualitative and quantitative family-based analyses of our ADHD families. For the quantitative analysis we used the additive model and the phenotypes were the mean centered variable of the BADDS total and cluster scores and the WURS scores. The DAT1 3'UTR-VNTR was considered as a biallelic polymorphism because the low occurrence of the rare alleles would have not provided any meaningful information. With these parameters FBAT (v 1.0) 
Table 1: Family-based Analysis of Both Qualitative and Quantitative Phenotypes of ADHD Families. The Statistics for the 10-Repeat Allele of the DAT1 3'UTR VNTR are Listed.

\begin{tabular}{lccrc}
\hline Phenotype $^{\mathbf{a}}$ & $\mathbf{S}^{\mathbf{b}}$ & $\mathbf{E}^{\mathbf{c}}$ & $\mathbf{Z}$ & $\mathbf{P}$ \\
\hline Qualitative: (Affection status) & 41.0 & 40.5 & 0.16 & .86 \\
Wender Utah Rating Scale Score & -197.0 & -127.5 & -1.67 & .09 \\
Brown ADD Scale Total Score & -102.6 & -115.83 & 0.28 & .77 \\
Brown ADD Scale Attention cluster & -15.8 & -24.84 & 0.68 & .49 \\
Brown ADD Scale Activation cluster & -26.0 & -29.0 & 0.27 & .78 \\
Brown ADD Scale Effort cluster & 255.0 & 263.1 & 0.27 & .78 \\
Brown ADD Scale Working Memory cluster & 132.8 & 142.74 & -0.55 & .57 \\
\hline
\end{tabular}

a The quantitative phenotype is derived from the Brown Attention Deficit Disorder Scale, adult version (Brown 1996) and from the Wender Utah Rating Scale (WURS) (Ward et al. 1993).

b $S$ represents the test statistic and expresses the count of 10 repeat alleles observed in the affected offspring depending on the parental genotypes. For the quantitative analysis, $\mathrm{S}$ is weighted to the phenotype measures.

${ }^{c} \mathrm{E}$ is the value expected for $\mathrm{S}$ under the null hypothesis of no association.
}

performs a quantitative analysis as described by Rabinowitz (1997). The DNA was not available for all parents of the probands thus the quantitative family-based strategy was not applicable to the entire sample. Therefore, to test the DAT1 3'UTR-VNTR as a QTL in all the probands we used the measured-genotype test (Boerwinkle et al. 1986). In this strategy, the mean quantitative trait values of the patients in each specific genotype group are compared using ANOVA. We compared the BADDS and WURS mean scores across three DAT1 3'UTR-VNTR genotype groups (9-9, 9-10, 10-10). ANOVA was performed using the Statistical Package for the Social Science (SPSS), version 10.

Table 2: The Mean Quantitative Trait Values of the Patients in Each Specific Genotype Group

\begin{tabular}{|c|c|c|c|c|c|}
\hline \multirow{2}{*}{$\begin{array}{l}\text { Brown and Wender } \\
\text { Scores }^{\mathrm{a}} \\
\text { Mean (S.D.) }\end{array}$} & \multirow{2}{*}{$\begin{array}{c}\text { Total sample }{ }^{\mathrm{b}} \\
\mathrm{n}=152\end{array}$} & \multicolumn{3}{|c|}{ Genotype } & \multirow{2}{*}{$\begin{array}{c}\text { Statistic }^{c} \\
\text { F }\end{array}$} \\
\hline & & 10-10 & $10-9$ & 9-9 & \\
\hline Activation & $19.86(5.22)$ & $20.17(5.22)$ & $19.41(4.91)$ & 20.31 (6.36) & 0.43 \\
\hline Male & $19.33(5.68)$ & $19.20(5.80)$ & $19.27(5.27)$ & $19.81(6.77)$ & \\
\hline Female & $20.86(4.10)$ & $21.48(4.06)$ & $19.71(4.17)$ & $23.00(2.64)$ & \\
\hline Attention & $20.48(5.22)$ & $21.20(4.63)$ & $19.75(5.33)$ & $20.42(6.63)$ & 1.29 \\
\hline Male & $20.10(5.64)$ & $20.61(4.77)$ & $19.56(5.84)$ & $20.31(7.14)$ & \\
\hline Female & $21.20(4.28)$ & $22.00(4.39)$ & $20.14(4.17)$ & $21.00(3.60)$ & \\
\hline Effort & $18.10(5.92)$ & $18.23(5.91)$ & $17.96(5.90)$ & 18.01 (6.39) & 0.48 \\
\hline Male & $18.51(5.93)$ & $18.10(6.19)$ & $19.00(5.37)$ & $18.18(6.99)$ & \\
\hline Female & $17.33(5.88)$ & $18.41(5.60)$ & $15.80(6.47)$ & $17.66(0.57)$ & \\
\hline Affect & $12.90(4.57)$ & $12.89(4.64)$ & $12.63(4.46)$ & $13.89(4.84)$ & 0.55 \\
\hline Male & $12.53(4.81)$ & $12.02(5.01)$ & $12.63(4.53)$ & $13.50(5.18)$ & \\
\hline Female & $13.60(4.04)$ & $14.06(3.87)$ & $12.61(4.39)$ & $16.00(1.00)$ & \\
\hline Working Memory & $12.36(4.28)$ & $12.97(3.80)$ & $12.10(4.27)$ & $11.10(5.61)$ & 1.65 \\
\hline Male & $11.89(4.59)$ & $12.41(4.06)$ & $11.95(4.52)$ & $10.50(5.89)$ & \\
\hline Female & $13.24(3.48)$ & $13.72(3.35)$ & $12.42(3.76)$ & $14.33(2.08)$ & \\
\hline BADDS Total & $83.74(21.35)$ & $85.50(20.02)$ & $81.87(21.01)$ & 83.84 (27.19) & 0.48 \\
\hline Male & $82.39(22.74)$ & $82.38(21.34)$ & $82.43(21.81)$ & $82.31(29.35)$ & \\
\hline Female & $86.26(18.42)$ & 89.68 (17.58) & 80.71 (19.69) & $92.00(8.71)$ & \\
\hline WURS & 57.09 (17.52) & 57.59 (18.35) & $55.92(16.87)$ & 59.36 (17.39) & 0.33 \\
\hline Male & $56.28(16.48)$ & $53.65(16.60)$ & 57.29 (15.47) & 59.75 (18.87) & \\
\hline Female & $58.61(19.41)$ & $62.92(19.53)$ & $53.04(19.56)$ & $57.33(6.50)$ & \\
\hline
\end{tabular}

Table 2 Note:

a Means are reported for the Brown ADD Scale Total Scores and Cluster symptom scores and the Wender Utah Rating Scale. Five different adult ADHD dimensions are present in the Brown scale (for more detail see text).

b The total sample is composed of 53 females and 99 males.

c ANOVA has been used to compare the mean scores. None of the analyses performed produced a significant difference of the means across the genotype groups at a $\mathrm{p}$ value $<0.05$. 

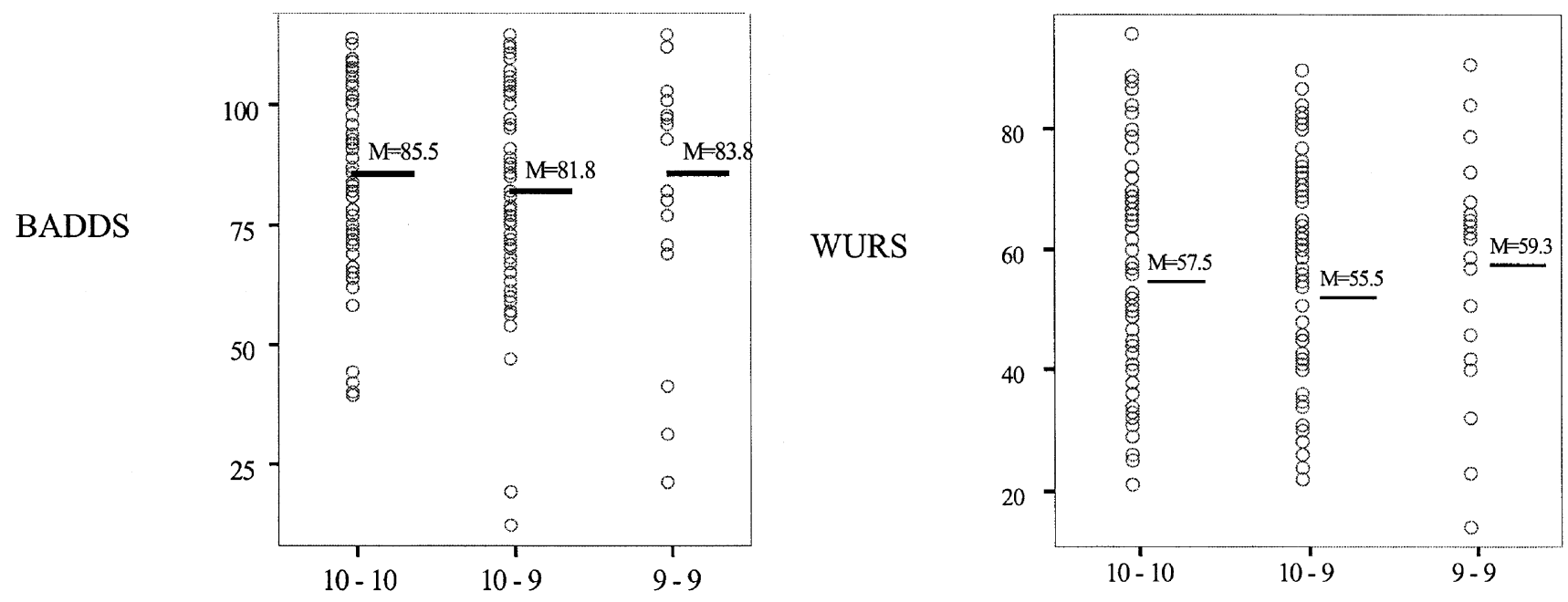

\section{DAT1 3'UTR-VNTR Genotypes}

Figure 1. Brown ADD Scale (BADDS) and Wender Utah Rating Scale (WURS) total scores and DAT1 genotypes. M indicates the mean for each of the genotype groups. No statistical significant differences were detected in DAT1 genotype groups for BADDS or WURS measures.

\section{RESULTS}

The family-based analysis of the DAT1 VNTR alleles did not reveal the presence of association with ADHD when the phenotype was considered as a qualitative trait $(\mathrm{Z}=0.16 ; p=.86)$. When the family-based analysis was conducted considering the ADHD phenotype as a quantitative trait no association was detected between DAT1 alleles and the Brown ADD cluster, or total scores, or WURS score (see Table 1). In the analysis of the total sample of singleton probands, when the means of the BADDS symptom clusters, or total scores, or the WURS scores were compared among the subjects according to the different DAT1 genotype groups, (as shown in Table 2, and Figure 1), no significant differences nor sex-specific effects were observed.

\section{DISCUSSION}

We were interested in testing for an association between the DAT1 VNTR alleles and ADHD in adults with the persistent variant of the disorder. Faraone et al. (2000) have suggested that the adult version of ADHD is associated with a higher genetic contribution since the relative risk is higher in family members of the patients with the persistent form of the disorder than in the relatives of child ADHD patients. It has been dem- onstrated that a higher relative risk confers stronger power of genetic association studies (Speer 1998), thus the persistent variant of ADHD arises as a promising phenotype for detection of susceptibility alleles. An example of successful use of a subset of high relative risk families to find an etiologic gene is represented in the case of early onset Alzheimer's Disease (Sherrington et al. 1995). Also, in the childhood ADHD study by Waldman and colleagues (Waldman et al. 1998) the association of the DAT1 10-repeat allele was reported to be stronger with the more severe form of the disorder. Therefore, it was important to test the DAT1 association in a sample of adult ADHD patients since the variant of ADHD that persists into adulthood can be considered a more severe subtype of the disorder. Another interesting aspect of the persistent form of ADHD lies in the fact that non-genetic risk factors such as adverse family environment that have been shown to increase risk for child ADHD (Rutter and Quinton 1977; Biederman et al. 1995) may inflate the heterogeneity of the clinical samples. Adverse family environment is believed to play a reduced role as a risk factor in adults and it is arguable that children with ADHD largely determined by the adverse family environment will outgrow the disorder. It is therefore likely that adult ADHD samples are characterized by a reduced etiologic heterogeneity. In other words, adult samples would have a lower phenocopy rate (i.e. lower proportion of subjects with the same phenotype determined by non-genetic factors). 
We were unable to replicate the association between the 10-repeat allele and ADHD. Furthermore, no correlation was found between the DAT1 3'UTR-VNTR alleles and ADHD severity or symptom scores as defined by the Brown ADD and the Wender Utah Rating Scale in a our sample of 152 adults with ADHD. At least five studies in four independent samples (Cook et al. 1995; Gill et al. 1997; Waldman et al. 1998; Daly et al. 1999; Curran et al. 2001) have reported the presence of association between the 10-repeat allele of the 3'UTR-VNTR of the DAT1 and ADHD in children. Four studies, however, did not replicate the association (Palmer et al. 1999; Holmes et al. 2000; Swanson et al. 2000; Roman et al. 2001). In a child study by Barr et al. (2001), initial analyses showed a nonsignificant increased number of transmissions for the 10repeat allele. However, when haplotypes made up of the 10-repeat allele and specific alleles from two single nucleotide polymorphisms located in intron nine and in exon nine were examined, an association with ADHD was found (Barr et al. 2001). Cook et al. (1995) reported an odds ratio of 2.6 for ADHD determined by the presence of the DAT1 10-repeat allele. The power of our sample of families considering the 10-repeat allele as the risk allele with an additive model conferred a power $>0.8$ for a significance level $=0.05$ considering both qualitative as well quantitative analysis as calculated by the program PBAT: Analytical Power Calculations for Family-Based Association Tests (PBAT, v 0.1 (Lange 2001).

The apparently conflicting evidence for association across different data sets represents a common trend of association studies in complex diseases. Aside from lack of appropriate statistical power, a number of factors may contribute to the inability to reproduce genetic association findings. In the case of multiple predisposing genes, population substructure or clinical heterogeneity, a risk allele may (for stochastic reasons) play a larger or smaller role in a given sample of patients, thus producing contrasting results. The specific characteristic of our sample, comprised of adult ADHD probands, may have determined the lack of association with the 10-repeat allele. The association reported by Waldman et al. (1998) that indicates a prominent role for the 10-repeat allele in the hyperactive subtype in children is not, strictly speaking, testable in our sample. In fact, the symptoms of the hyperactive subtype largely disappear in approximately $80 \%$ of ADHD children as they grow up (Biederman et al. 2000). In our sample of adult patients only a small number of hyperactive ADHD patients were present and thus the testing of this specific hypothesis was not feasible. Another possible origin of the contrasting results in the DAT1 and ADHD association studies is the presence of the recently described single nucleotide polymorphism located $135 \mathrm{bp}$ downstream from the $3^{\prime}$ end of the DAT1 VNTR (Miller and Madras 2002); that none of the ADHD association studies to date have analyzed. If this SNP is common in the population its analysis would be essential in the ADHD samples considering its proximity to the VNTR and its preliminary evidence of its function in the regulation of the gene expression (Miller and Madras 2002). The same study (Miller and Madras 2002) together with two concurrent publications (Fuke et al. 2001; Michelhaugh et al. 2001) are also suggesting a functional role for the DAT1 VNTR. However, because the two studies that have assessed the influence of the repeat length on the control of gene expression are conflicting (Fuke et al. 2001; Miller and Madras 2002), additional work is necessary to clarify the exact functional role of the $3^{\prime}$ UTR VNTR of DAT1.

In summary, the results from the present study together with the results from previous investigations on the role of the DAT1 VNTR in ADHD are variable, making any conclusions speculative at the present time. While the use of haplotypes may increase the information at the DNA level, the increased degrees of freedom created by the use of haplotypes requires a larger sample size in order to have sufficient statistical power.

\section{ACKNOWLEDGMENTS}

PM is a Fellow of the Medical Research Council of Canada and the Schizophrenia Society of Canada. The work was supported by Medical Research Council of Canada grant \#PG11121 (JLK). The authors would like to acknowledge the valuable work done by Ruth Barton and Ramesh Shah in assisting the clinical assessment of the patients that participated in this study and Maria Neves Pereira and Nicole King for their assistance in the laboratory procedure.

\section{REFERENCES}

Abecasis GR, Cardon LR, Cookson WO (2000): A general test of association for quantitative traits in nuclear families. Am J Hum Genet 66:279-292

Allison DB (1997): Transmission-disequilibrium tests for quantitative traits. Am J Hum Genet 60:676-690

American Psychiatric Association (1994): Diagnostic and Statistical Manual of Mental Disorder, 4th ed. Washington, DC, American Psychiatric Association Press

Bacanu SA, Devlin B, Roeder K (2000): The power of genomic control. Am J Hum Genet 66:1933-1944

Barkley RA, Fischer M, Edelbrock CS, Smallish L (1990): The adolescent outcome of hyperactive children diagnosed by research criteria: I. An 8-year prospective follow-up study. J Am Acad Child Adolesc Psychiatry 29:546-557

Barr CL, Xu C, Kroft J, Feng Y, Wigg K, Zai G, Tannock R, Schachar R, Malone M, Roberts W, Nothen MM, Grunhage F, Vandenbergh DJ, Uhl G, Sunohara G, King N, Kennedy JL (2001): Haplotype study of three polymorphisms at the dopamine transporter locus confirm linkage to attention-deficit/hyperactivity disorder. Biol Psychiatry 49:333-339 
Biederman J, Faraone SV, Keenan K, Knee D, Tsuang MT (1990): Family-genetic and psychosocial risk factors in DSM-III attention deficit disorder. J Am Acad Child Adolesc Psychiatry 29:526-533

Biederman J, Faraone SV, Spencer T, Wilens T, Norman D, Lapey KA, Mick E, Lehman BK, Doyle A (1993): Patterns of psychiatric comorbidity, cognition, and psychosocial functioning in adults with attention deficit hyperactivity disorder. Am J Psychiatry 150:1792-1798

Biederman J, Mick E, Faraone SV (2000): Age-dependent decline of symptoms of attention deficit hyperactivity disorder: impact of remission definition and symptom type. Am J Psychiatry 157:816-818

Biederman J, Milberger S, Faraone SV, Kiely K, Guite J, Mick E, Ablon S, Warburton R, Reed E (1995): Family-environment risk factors for attention-deficit hyperactivity disorder. A test of Rutter's indicators of adversity. Arch Gen Psychiatry 52:464-470

Biederman J, Newcorn J, Sprich S (1991): Comorbidity of attention deficit hyperactivity disorder with conduct, depressive, anxiety, and other disorders. Am J Psychiatry 148:564-577

Biederman J, Spencer T (1999): Attention-deficit/hyperactivity disorder (ADHD) as a noradrenergic disorder. Biol Psychiatry 46:1234-1242

Boerwinkle E, Chakraborty R, Sing CF (1986): The use of measured genotype information in the analysis of quantitative phenotypes in man. I. Models and analytical methods. Ann Hum Genet 50:181-194

Brown TE (1996): Brown ADD Scale. The Psychological Corporation. San Antonio, Texas, Harcourt Brace \& Company.

Castellanos FX (1997): Toward a pathophysiology of attention-deficit/hyperactivity disorder. Clin Pediatr (Phila) 36:381-393

Cook EH Jr, Stein MA, Krasowski MD, Cox NJ, Olkon DM, Kieffer JE, Leventhal BL (1995): Association of attention-deficit disorder and the dopamine transporter gene. Am J Hum Genet 56:993-998

Curran S, Mill J, Tahir E, Kent L, Richards S, Gould A, Huckett L, Sharp J, Batten C, Fernando S, Ozbay F, Yazgan Y, Simonoff E, Thompson M, Taylor E, Asherson P (2001): Association study of a dopamine transporter polymorphism and attention deficit hyperactivity disorder in UK and Turkish samples. Mol Psychiatry 6:425-428

Daly G, Hawi Z, Fitzgerald M, Gill M (1999): Mapping susceptibility loci in attention deficit hyperactivity disorder: preferential transmission of parental alleles at DAT1, DBH and DRD5 to affected children. Mol Psychiatry 4:192-196

Faraone SV, Biederman J, Monuteaux MC (2000): Toward guidelines for pedigree selection in genetic studies of attention deficit hyperactivity disorder. Genet Epidemiol 18:1-16

Fuke S, Suo S, Takahashi N, Koike H, Sasagawa N, Ishiura S (2001): The VNTR polymorphism of the human dopamine transporter (DAT1) gene affects gene expression. The Pharmacogenomics Journal 1:152-156

Gatley SJ, Pan D, Chen R, Chaturvedi G, Ding YS (1996): Affinities of methylphenidate derivatives for dopamine, norepinephrine and serotonin transporters. Life Sci $58: 231-239$
Gill M, Daly G, Heron S, Hawi Z, Fitzgerald M (1997): Confirmation of association between attention deficit hyperactivity disorder and a dopamine transporter polymorphism. Mol Psychiatry 2:311-313

Gillis JJ, Gilger JW, Pennington BF, DeFries JC (1992): Attention deficit disorder in reading-disabled twins: evidence for a genetic etiology. J Abnorm Child Psychol 20:303-315

Giros B, el Mestikawy S, Godinot N, Zheng K, Han H, YangFeng T, Caron MG (1992): Cloning, pharmacological characterization, and chromosome assignment of the human dopamine transporter. Mol Pharmacol 42:383-390

Gittelman R, Mannuzza S, Shenker R, Bonagura N (1985): Hyperactive boys almost grown up. I. Psychiatric status. Arch Gen Psychiatry 42:937-947

Goodman R, Stevenson J (1989): A twin study of hyperactivity-II. The aetiological role of genes, family relationships and perinatal adversity. J Child Psychol Psychiatry 30:691-709

Hay D, McStephen M, Levy F (2001): Introduction to the Genetic Analysis of Attentional Disorder. Philadelphia, Brunner-Routledge

Holmes J, Payton A, Barrett JH, Hever T, Fitzpatrick H, Trumper AL, Harrington R, McGuffin P, Owen M, Ollier W, Worthington J, Thapar A (2000): A familybased and case-control association study of the dopamine D4 receptor gene and dopamine transporter gene in attention deficit hyperactivity disorder. Mol Psychiatry 5:523-530

Horvath S, Xu X, Laird NM (2001): The family based association test method: strategies for studying general genotype-phenotype associations. Eur J Hum Genet 9:301-306

Kang AM, Palmatier MA, Kidd KK (1999): Global variation of a 40-bp VNTR in the 3'-untranslated region of the dopamine transporter gene (SLC6A3). Biol Psychiatry 46:151-160

Lake SL, Blacker D, Laird NM (2000): Family-based tests of association in the presence of linkage. Am J Hum Genet 67:1515-1525

Lange C (2001): PBAT: Analytical Power Calculations for Family-Based Association Tests (v 0.1). Department of Biostatistics, Harvard School of Public Health

Levy F, Hay DA, McStephen M, Wood C, Waldman I (1997): Attention-deficit hyperactivity disorder: a category or a continuum? Genetic analysis of a large-scale twin study. J Am Acad Child Adolesc Psychiatry 36:737-744

Maher BS, Marazita ML, Moss HB, Vanyukov MN (1999): Segregation analysis of attention deficit hyperactivity disorder. Am J Med Genet 88(1):71-78

Mannuzza S, Klein RG, Addalli KA (1991): Young adult mental status of hyperactive boys and their brothers: a prospective follow-up study. J Am Acad Child Adolesc Psychiatry 30:743-751

Michelhaugh SK, Fiskerstrand C, Lovejoy E, Bannon MJ, Quinn JP (2001): The dopamine transporter gene (SLC6A3) variable number of tandem repeats domain enhances transcription in dopamine neurons. J Neurochem 79:1033-1038

Miller GM, Madras BK (2002): Polymorphisms in the 3'untranslated region of human and monkey dopamine transporter genes affect reporter gene expression. Mol Psychiatry 7:44-55 
Mitchell RJ, Howlett S, Earl L, White NG, McComb J, Schanfield MS, Briceno I, Papiha SS, Osipova L, Livshits G, Leonard WR, Crawford MH (2000): Distribution of the 3' VNTR polymorphism in the human dopamine transporter gene in world populations. Hum Biol 72:295-304

Muglia P, Jain U, Macciardi F, Kennedy JL (2000): Adult attention deficit hyperactivity disorder and the dopamine D4 receptor gene. Am J Med Genet 96:273-277

Palmer CG, Bailey JN, Ramsey C, Cantwell D, Sinsheimer JS, Del'Homme M, McGough J, Woodward JA, Asarnow R, Asarnow J, Nelson S, Smalley SL (1999): No evidence of linkage or linkage disequilibrium between DAT1 and attention deficit hyperactivity disorder in a large sample. Psychiatr Genet 9:157-160

Pliszka SR, McCracken JT, Maas JW (1996): Catecholamines in attention-deficit hyperactivity disorder: current perspectives. J Am Acad Child Adolesc Psychiatry 35: 264-272

Rabinowitz D (1997): A transmission disequilibrium test for quantitative trait loci. Hum Hered 47:342-350

Roman T, Schmitz M, Polanczyk G, Eizirik M, Rohde LA, Hutz MH (2001): Attention-deficit hyperactivity disorder: a study of association with both the dopamine transporter gene and the dopamine D4 receptor gene. Am J Med Genet 105:471-478

Rutter M, Quinton D (1977): Psychiatric Disorder: Ecological Factors and Concepts of Causation. Amsterdam, The Netherlands, North-Holland Publishing Co.

Sherman DK, Iacono WG, McGue MK (1997): Attention-deficit hyperactivity disorder dimensions: a twin study of inattention and impulsivity-hyperactivity. J Am Acad Child Adolesc Psychiatry 36:745-753

Sherrington R, Rogaev EI, Liang Y, Rogaeva EA, Levesque G, Ikeda M, Chi H, Lin C, Li G, Holman K, Tsuda T, Mar L, Foncin J-F, Bruni AC, Montesi MP, Sorbi S, Rainero I, Pinessi L, Nee L, Chumakov I, Pollen D, Brookes A, Sanseau P, Polinsky RJ, Wasco W, Da Silva HAR, Haines JL, Pericak-Vance MA, Tanzi RE, Roses AD, Fraser PE, Rommens JM, St George-Hyslop PH (1995): Cloning of a gene bearing missense mutations in earlyonset familial Alzheimer's disease. Nature 375:754-760
Speer M (1998): Sample Size and Power. New York, Wiley \& Sons

Sprich S, Biederman J, Crawford MH, Mundy E, Faraone SV (2000): Adoptive and biological families of children and adolescents with ADHD. J Am Acad Child Adolesc Psychiatry 39:1432-1437

Swanson JM, Flodman P, Kennedy J, Spence MA, Moyzis R, Schuck S, Murias M, Moriarity J, Barr C, Smith M, Posner M (2000): Dopamine genes and ADHD. Neurosci Biobehav Rev 24:21-25

Thapar A, Holmes J, Poulton K, Harrington R (1999): Genetic basis of attention deficit and hyperactivity. Br J Psychiatry 174:105-111

Vandenbergh DJ, Persico AM, Hawkins AL, Griffin CA, Li X, Jabs EW, Uhl GR (1992): Human dopamine transporter gene (DAT1) maps to chromosome 5p15.3 and displays a VNTR. Genomics 14:1104-1106

Waldman ID, Robinson BF, Rowe DC (1999): A logistic regression based extension of the TDT for continuous and categorical traits. Ann Hum Genet 63:329-340

Waldman ID, Rowe DC, Abramowitz A, Kozel ST, Mohr JH, Sherman SL, Cleveland HH, Sanders ML, Gard JM, Stever C (1998): Association and linkage of the dopamine transporter gene and attention- deficit hyperactivity disorder in children: heterogeneity owing to diagnostic subtype and severity. Am J Hum Genet 63:1767-1776

Ward MF, Wender PH, Reimherr FW (1993): The Wender Utah Rating Scale: an aid in the retrospective diagnosis of childhood attention deficit hyperactivity disorder. Am J Psychiatry 150:885-890

Weiss G, Hechtman L, Milroy T, Perlman T (1985): Psychiatric status of hyperactives as adults: a controlled prospective 15-year follow-up of 63 hyperactive children. J Am Acad Child Psychiatry 24:211-220

Weiss M, Hechtman L, Weiss G (2000): ADHD in parents. J Am Acad Child Adolesc Psychiatry 39:1059-1061

Welner Z, Welner A, Stewart M, Palkes H, Wish E (1977): A controlled study of siblings of hyperactive children. J Nerv Ment Dis 165:110-117

Willerman L (1973): Activity level and hyperactivity in twins. Child Dev 44:288-293 